\title{
Eye-Fixation-Related Potentials: Insight into Parafoveal Processing
}

\author{
Thierry Baccino and Yves Manunta
}

University of Nice Sophia-Antipolis, France

\begin{abstract}
This paper presents a new methodology for studying cognition, which combines eye movements (EM) and event-related potentials (ERP) to track the cognitive processes that occur during a single eye fixation. This technique, called eye-fixation-related potentials (EFRP), has the advantage of coupling accurate time measures from ERPs and the location of the eye on the stimulus, so it can be used to disentangle perceptual/attentional/cognitive factors affecting reading. We tested this new technique to describe the controversial parafoveal-on-foveal effects on reading, which concern the question of whether two consecutive words are processed in parallel or sequentially. The experiment directly addressed this question by looking at whether semantic relatedness on a target word in a reading-like situation might affect the processing of a prime word. Three pair-word conditions were tested: A semantically associated target word (horse-mare), a semantically nonassociated target word (horse-table) and a nonword (horse-twsui); EFRPs were compared for all conditions. The results revealed that early ERP components differentiated word and nonword processing within $119 \mathrm{~ms}$ postfixation (N1 component). Moreover, the amplitude of the right centrofrontal P140 varied as a function of word type, being larger in response to nonassociated words than to nonwords. This component might index a spatial attention shift to the target word and its visual categorization, being highly sensitive to orthographic regularity and "illformedness" of words. The P2 consecutive component (peaking at $215 \mathrm{~ms}$ ) differentiated associated words and nonassociated words, which can account for the semantic parafoveal effect. The EFRP technique, therefore, appears to be fruitful for establishing a time-line of early cognitive processes during reading.
\end{abstract}

Keywords: reading, eye movement, ERP, EFRP, parafoveal processing

One of the main questions in reading is whether two adjacent words are processed simultaneously or consecutively; underlying this question are the elements of the time course of lexical processing, attention allocation, and saccade programming. There is considerable debate about the timing of these processes in reading. Several models of eye guidance in reading postulate the decoupling of attentional processing and eye-movement programming (Morrison, 1984; Reichle, Pollatsek, Fisher, \& Rayner, 1998; Reichle, Rayner, \& Pollatsek, 2002). For example, in Morrison's model, attention shifts to the next word once the fixated word has been accessed, and the same signal serves to initiate the programming of the next saccade. On the other hand, other models hypothesize parallel processing, claiming that there is at least some overlapping of saccade programming and lexical access (Engbert, Longtin, \& Kliegl, 2002). But what, exactly, are the conditions of reading? A large body of research using eye-movement methodology has shown that the average duration of fixation on a word (around $250 \mathrm{~ms}$ ) constrains the amount of time available for lexical processing and oculomotor operations (Rayner, 1998). The time required to program a saccadic eye movement is of the same order of amplitude $(150 \mathrm{~ms})$ as the lexical processing time of a single word (150$300 \mathrm{~ms}$ ). Lexical processing takes place within the first 100-150 ms (Sereno, Rayner, \& Posner, 1998), gradually making room for attention shifting and saccade programming. Hence, it seems clear that these temporal constraints involve at least some parallel processing mixed in with lexical processing, attention allocation, and eye-movement programming.

One possible way of testing whether parallel or sequential processing takes place during reading is to investigate the presence of parafoveal-on-foveal effects (Inhoff, Starr, \& Shindler, 2000; Kennedy, Pynte, \& Ducrot, 2002; Murray, 1998). Parafoveal-on-foveal effects occur when the processing of the next word (word on the right) affects the processing of the fixated word. Models based on the assumption that attention is allocated serially to different words cannot predict parafoveal-on-foveal effects because attention is not allocated to the parafoveal word until the foveal word has been processed. There are many studies in the literature that argue either for sequential processing (Morrison, 1984; Reichle et al., 1998) or for parallel processing (Engbert \& Kliegl, 2001; Engbert et al., 2002; Inhoff et al., 2000) by manipulating several visual (typography, display polarity) or lexical 
(frequency, plausibility, semantic association) factors. All of the data were obtained using an eye-tracking methodology, sometimes with a complex experimental presentation mode (contingent presentation). However, while eye-movement methodology is well suited to evaluating cognitive processing during reading, it is more difficult to disentangle attention and lexical processing when this type of technique is used. For example, fixation duration in reading is a rather broad measure that reflects the lexical processing of a fixated word, but it also reflects some effects of the next word to be fixated (parafoveal effects), and some spill-over effects caused by late processing of the previous word.

In a recent paper, Sereno and Rayner (2003) were looking for 'the holy grail' of cognitive measurement and claimed that event-related potentials (ERPs) and eyemovement (EM) methodologies might be good candidates for studying reading. Their complementarities in the temporal and spatial domains seemed to offer the possibility of finding out precisely when and where different cognitive operations occur in a line of text. Eye movements during reading reflect cognitive processes from one moment to the next and ERP can detect early activation following stimulus presentation. For example, we can find out which word in a line of text the reader fixates on, and potentially use ERPs to separate lexical and postlexical processes during word identification (Sereno, Brewer, \& O'Donnell, 2003). In fact, both EM and ERPs give temporal measurements, but EM (fixation duration) describes a summation of all cognitive processing occurring during identification while ERPs show the sequence of the processes. The techniques used in a few papers (Sereno \& Rayner, 2003; Sereno et al., 1998) have required running two experiments in parallel: One using EM and one using ERP, but with different subjects. With this matching data, interesting findings have shown that early components $(\mathrm{P} 1, \mathrm{~N} 1, \mathrm{P} 2)$ are sensitive to lexical processing as early as $100 \mathrm{~ms}$ after stimulus presentation and to context effects as early as $132 \mathrm{~ms}$ (132 to $192 \mathrm{~ms}$ ). We attempt to go further with this methodology by presenting here a new potential improvement in cognitive measurement based on a direct mapping between ERP and EMs during a mimicked reading task. While others have tried to approach the problem by indirect methods using EOG (Joyce, Gorodnitsky, King, \& Kutas, 2002; Kazai \& Yagi, 1999; Yagi, Imanishi, Konishi, Akashi, \& Kanaya, 1998; Yagi \& Ogata, 1995) or similar materials in separate studies (Sereno \& Rayner, 2003), we have made these measurements directly by coupling an infrared eyetracker and an EEG, and synchronizing them for data collection. Usually, ERPs are stimuluslocked averages of the electroencephalogram across many presentations of stimuli. We averaged EEG from fixation onset instead of from stimulus presentation (using EFRPs) in a temporal window lasting the duration of a fixation. The main purpose was to determine whether this technique can distinguish attention allocation to the next word from the lexical processing of the fixated word, and whether any semantic processing can take place in the parafoveal field. Participants read two words (prime-target). The target word was a word that was semantically associated to the prime (horse-mare), a nonword (horse-twsui), or a word that was not semantically associated to the prime (horsetable).

\section{Methods}

\section{Subjects}

Twenty healthy volunteers (11 females and 9 males) between the ages of 22 and 38 (mean age 27) participated in the experiment. These were all students in psychology (mainly 3rd year and postgraduate) and native speakers of French. All participants had normal, uncorrected visual acuity.

\section{Data Acquisition}

\section{Electrophysiological Recording (ERP)}

A total of 22 active, tin, nonpolarizable $\mathrm{Ag} / \mathrm{AgCl}$ electrodes were held in place on the scalp by an elastic cap (Electro-cap International Inc.) and located at standard positions according to the International 10/20 system (Jasper, 1958). The scalp was divided into four areas across the hemispheres, each containing the electrodes given in parentheses: A frontal area (FC1, F3, FC3, FC2, F4, FC4), a central area (C3, C1, CP1, C4, C2, CP2), a posterior area $(\mathrm{P} 3, \mathrm{P} 4, \mathrm{O} 1, \mathrm{O} 2, \mathrm{CP} 3, \mathrm{CP} 4)$, and a mid-line area $(\mathrm{Oz}, \mathrm{Pz}$, $\mathrm{Cz}, \mathrm{Fz}$ ). Electrodes placed on the left and right ear lobs were used as reference points. Two electrodes were also placed laterally and below the left eye to monitor horizontal and vertical eye movements, respectively. Impedance was kept below $5 \mathrm{~K} \Omega$ on every electrode

The EEG signal was amplified by a BrainAmp MR 32 (BrainProducts $\mathrm{GmbH}$, Munich) with a $0.01-100 \mathrm{~Hz}$ bandpass and continuously sampled at $1 \mathrm{KHz}$ by an analog-to-digital converter. The EEG signal was monitored by the Brain Vision Recorder ${ }^{\mathrm{TM}}$ software and was stored on computer for off-line analyses.

\section{Eye-Movement (EM) Recording}

EM were monitored by means of an infrared photoelectric system (Dr. Bouis, Karlsruhe, Germany), which determines the center of gravity of the infrared light reflected by the pupil. This system provided a near-linear output for a horizontal visual angle of $\pm 6^{\circ}$, with an accuracy level 
better than 2 minutes of arc. The signal was digitized every millisecond using a PC 1200 A/D Converter (National Instruments) and recorded for off-line analysis. Recording was from the right eye, although viewing was binocular. The participant's head was constrained by use of a forehead and chin frame. Calibration of the eyetracker was carried out using a 3-point calibration procedure.

\section{EFRP Recording (Combining EM and ERP Measures)}

Two computers were connected through their parallel ports (Figure 1). The first computer was used for stimulus presentation and the eye-movement acquisition. This computer contained a Matrox Millenium G450 DualHead graphic board to manage two displays: One monitor was devoted to stimulus presentation and the other to monitoring the eye-tracking recording (calibration). The second computer, located in an adjacent room, was used to collect the EEG signals by means of the Brain Vision Recorder ${ }^{\mathrm{TM}}$ software.

The coupling of the two systems was achieved by sending a synchronization signal (TTL Pulse) as soon as the stimulus was presented on the display (stimulus onset). The synchronization signal enabled the EM and EEG signals to be recorded simultaneously. Both recordings were acquired continuously in a temporal window of $2600 \mathrm{~ms}$ throughout the experiment.

\section{Linguistic Material and Display Presentation}

Three sets of 72 prime words were generated. Each foveal prime (word $n$ ) was presented with a semantically associated or nonassociated target word, or a nonword (word $n+1$ ) that was matched in length up to a two-letter difference. The choice of associated primes and targets was made based on the results of preliminary study in which 60 participants were presented with a list of 100 words selected from the associative norms of French (Cornuejols, 1998).

Seventy-two word pairs were then selected to construct the experimental lists. All selected prime words were between 3 and 10 letters long, with a mean length of 5.9 letters and target words had a mean length of 6.3 letters. All had a high frequency of occurrence in the language (averaging 120 occurrences per million; Trésor de la Langue Française). The target words did not have strongly competing multiple meanings, which is known to affect word processing time (Jastrzembski, 1981; Jastrzembski \& Stanners, 1975) and to lead to pseudofrequency effects (Millis \& Button, 1989). None of the targets had orthographical neighbors so that neighborhood frequency effects could not occur (Grainger, 1990).

The words were presented in dark letters on a white background. Screen luminance was adjusted to a comfortable level throughout the experiment. The room was dark, except for a dim indirect light source.

\section{Procedure}

Upon arriving for an experimental session, each subject was seated comfortably at a distance of $60 \mathrm{~cm}$ from the computer screen. Then the calibration phase took place, which required the participant to fix his or her gaze as accurately as possible on a cross that appeared in three

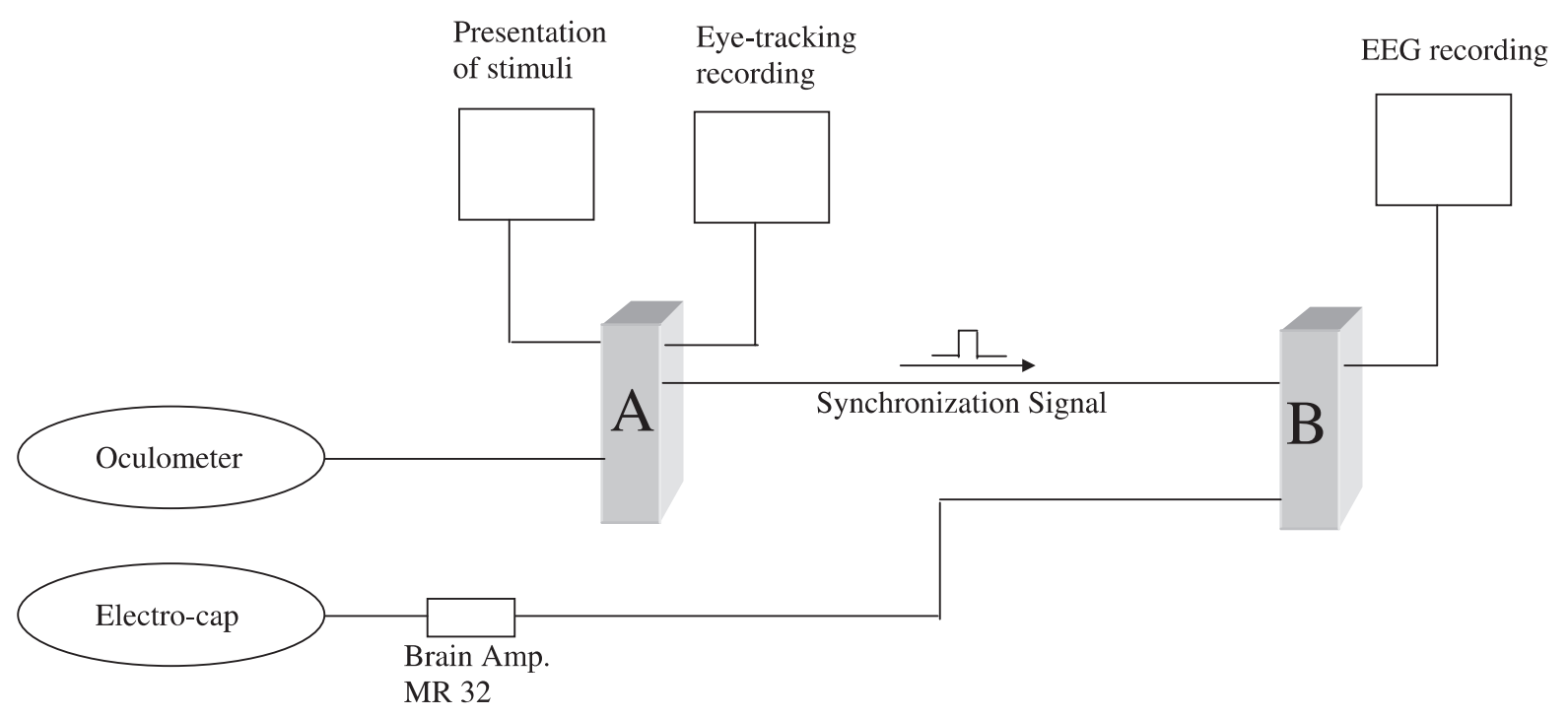

Figure 1. Experimental set-up for the eye-fixation-related potentials (EFRP). A TTL pulse synchronized two computers. The first computer (A) was devoted to the presentation of stimuli and eye-movements recording while the second computer (B) stored the EEG. 


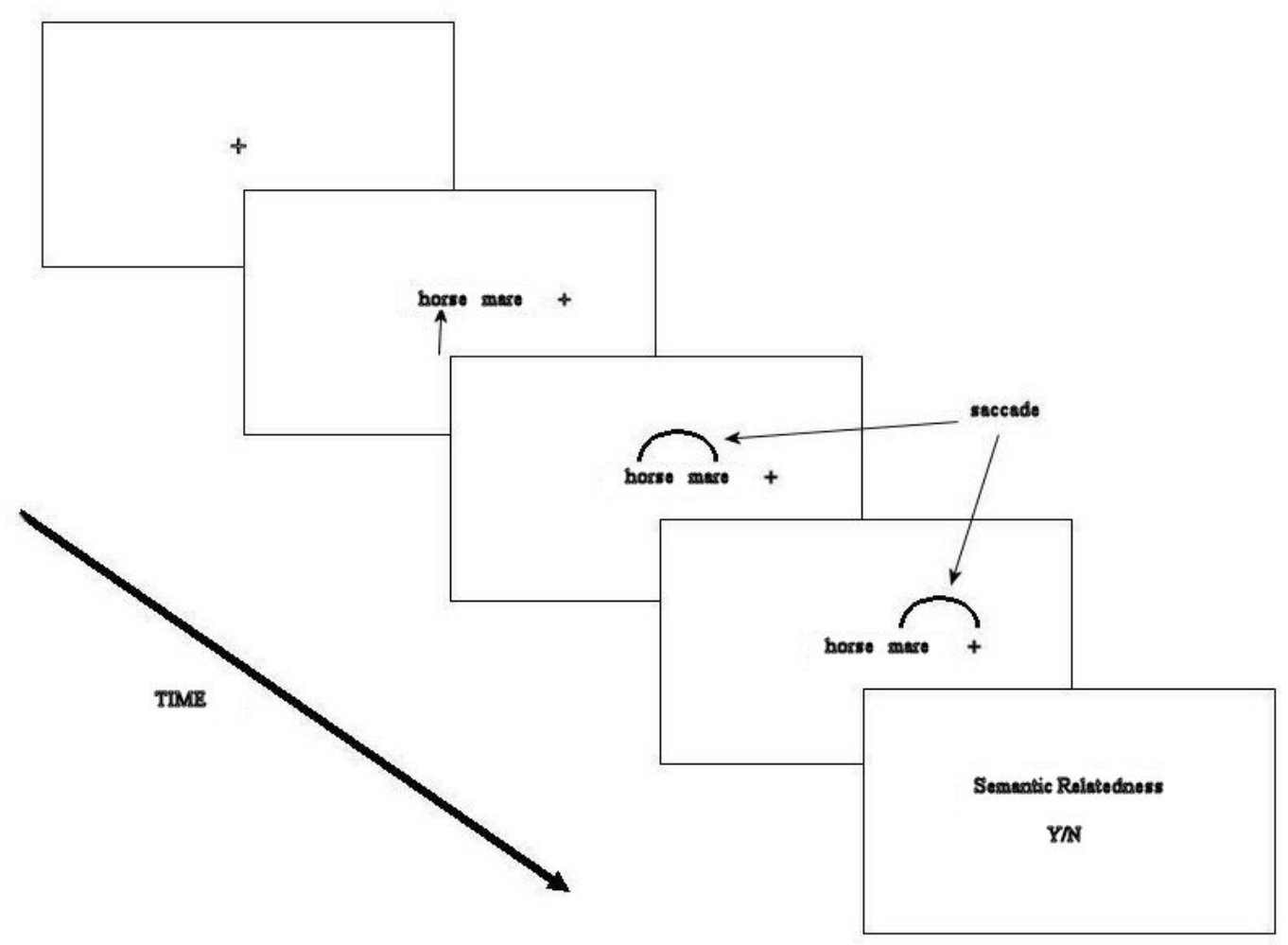

Figure 2. Schematic stimulus display for the experiment. Subjects fixated a cross centered on the screen and when a fixation was detected (contingent display), the cross was replaced by the first word horse while parafoveal word mare and the cross on the right were displayed simultaneously. Stimuli were remained visible for $2600 \mathrm{~ms}$.

successive positions along the middle horizontal line of the screen (where the words would later be displayed). As soon as the experimenter pressed a key, the point disappeared and reappeared in the next screen position. The eye position used for calibration was the one recorded at the moment when the experimenter pressed the key. The calibration phase was repeated until the difference between the different positions of the points on the screen and the corresponding eye locations was less than $0.2^{\circ}=2 \mathrm{~min}$ of $\operatorname{arc}\left(1^{\circ}=28\right.$ pixels $\left.=1.05 \mathrm{~cm}\right)$. After calibration, the subjects were given 6 practice trials followed by a total of 144 experimental trials ( 72 word pairs repeated twice). Each session lasted approximately 25 min.

At the beginning of each trial, the subject was asked to fix his/her gaze on a cross centered on the display. When a fixation was detected in a region of plus or minus $2 \mathrm{~min}$. of arc around the cross, the stimulus appeared (word pair plus a right-located cross for $2600 \mathrm{~ms}$ ). The middle of the left prime (foveal) word exactly replaced the cross to make sure that the subject's fixation position was in the center of the word. The distance between the centers of the two words was equal to $3^{\circ}$ of visual angle and for each word the visual angle was, respectively, equal to $1.69^{\circ}$ (Prime) and $1.8^{\circ}$ (Target). The partici- pants were instructed to read each word and to fixate the cross on the right to complete the task. The subject's task was to make semantic association judgments of word pairs as quickly as possible, then press one of the two buttons on the mouse, each one assigned to a yes or no response. The next trial began immediately after the response was given.

\section{Data Analysis}

\section{EM Analysis}

EM data always require a reduction phase that breaks the EM samples down into a set of fixations. The reduction phase was done off-line. Fixations were detected by means of a saccade-triggering algorithm. The onset and offset of each saccade were found using the following velocity-based algorithm (Stampe, 1993). At each sampling point in time $\left(\mathrm{t}_{\mathrm{i}}\right)$, we tested two logical conditions for the actual eye position signal, $S\left(t_{i}\right)$, in millivolts: $\operatorname{abs}\left[\mathrm{S}\left(\mathrm{t}_{\mathrm{i}-3}\right)-\mathrm{S}\left(\mathrm{t}_{\mathrm{i}}\right)\right]>\mathrm{T}_{\mathrm{sacc}}$ and abs $\left[\mathrm{S}\left(\mathrm{t}_{\mathrm{i}-1}\right)-\mathrm{S}\left(\mathrm{t}_{\mathrm{i}}\right)\right]<\mathrm{T}_{\text {fix }}$. If both conditions were fulfilled, a sampling point was assumed to fall within the saccade. The first condition was fulfilled whenever the voltage exceeded a chosen threshold value of $\mathrm{T}_{\text {sacc }}=12 \mathrm{mV}$. The second condition, the 
value $T_{\text {fix }}=10 \mathrm{mV}$, was used to prevent stretching of saccades and erosion of the fixation following the saccade; this resulted in a threshold velocity of about $30 \mathrm{deg} / \mathrm{s}$. Once the saccades had been detected, the fixations were isolated. Some of the fixations had to be removed from the data set because of eye blinks, drifts, or glides, or whenever the fixation duration was less than $100 \mathrm{~ms}$. These fixations, which were $4 \%$ of the total number of fixations, were replaced by the mean values of the corresponding condition in order to avoid missing values in the statistical analyses. The set of isolated fixations were used later to segment the EEG.

EM statistical analyses were done only for fixations detected on the prime word. Analyses of variance were calculated on gaze duration (sum of all fixations occurring on the prime word, including reinspections) and first-pass duration (sum of all fixations, excluding reinspections). ANOVAs were carried out using a $3 \times 48$ design with semantic association (associated, nonword, nonassociated) and items (48 per condition - repetition factor). Greenhouse-Geisser corrections of the significance levels were applied for all repeated measures.

\section{EFRP Analysis}

EEGs were analyzed off-line with the Brain Vision Analyzer $^{\mathrm{TM}}$ software (BrainProducts $\mathrm{GmbH}$, Munich). The EEG signal was recorded continuously throughout the experiment and a digital $0.1-40 \mathrm{~Hz}$ bandpass filter was applied before analysis. One of the preliminary stages in the analysis of the evoked potentials was to segment the EEG by dividing it into sections of equal duration (temporal windows) relative to a reference marker. We used the onset of the first fixation on the prime word as the reference marker. For each trial, this marker was time locked with the corresponding synchronization signal sent during acquisition. Once the EEG was segmented, all segments corresponding to the same experimental condition were averaged. These EFRPs were quantified by calculating the mean amplitude (relative to the $100 \mathrm{~ms}$ prestimulus baseline) of the voltage points in two temporal windows: 0-200, and 0-300 ms after fixation onset. Trials were rejected when the duration of a fixation did not fill one of these temporal windows (for example, a $250 \mathrm{~ms}$ fixation duration filled the $200 \mathrm{~ms}$ temporal window but not the $300 \mathrm{~ms}$ window) or when they corresponded to movement artifacts $(\mathrm{EOG} \pm 20 \mu \mathrm{v}$ and EEG $\pm 40 \mu \mathrm{v})$. The first temporal window $(0-200 \mathrm{~ms})$ was selected based on the following identifiable visual ERP components: P1 (peak 60-90 ms) and N1 (peak 110-140 ms). These ERP components showed the largest amplitudes around the left occipital area (under electrode O1). An ANOVA was performed on this electrode with semantic association as a within-subject factor (as- sociated, nonword, nonassociated). In the second temporal window (0-300 ms), two additional components could be observed: P2 (peak 200-230 ms) and N2 (240-280 ms) on central and frontal sites of both hemispheres. For this time window, amplitude and latencies of these peaks were measured under the following electrodes: A left central area $(\mathrm{C} 1, \mathrm{C} 3, \mathrm{CP} 1)$, a left frontal area (F3, FC1, FC3), a left posterior area (O1, CP3, P3), a right central area $(\mathrm{C} 2, \mathrm{C} 4, \mathrm{CP} 2)$, a right frontal area $(\mathrm{F} 4$, $\mathrm{FC} 2, \mathrm{FC} 4)$, and a right posterior area $(\mathrm{O} 2, \mathrm{CP} 4, \mathrm{P} 4)$. Repeated-measures ANOVAs with Greenhouse-Geisser correction were carried out using hemisphere (left vs. right), site (frontal vs. central vs. posterior), electrode (3 per site), and semantic association (associated, nonword, nonassociated) as within-subject factors.

\section{Results}

All results reported here pertain to the processing of the first word during word-pair presentation, since we were interested in parafoveal-on-foveal effects.

\section{Behavioral Results}

The accuracy rates (averaged over all subjects) for nonsemantic association, semantic association, and nonwords were 94\%, 99\%, and 97\%, respectively. The difference in accuracy rates between these three conditions was significant; $F(2,38)=6.21, p<.01$. Planned comparisons between conditions showed greater accuracy for nonwords than for associated words; $F(1,19)=5.31$, $p<.05$; and for nonassociated words; $F(1,19)=13.94$, $p<.001$. The difference between associated and nonassociated words did not reach significance; $F(1,19)=$ 2.03 , ns. Moreover, there was no reliable difference on response times $(F<1$; associated $=582 \mathrm{~ms}$, nonassociated $=593 \mathrm{~ms}$, nonword $=567 \mathrm{~ms}$ ).

\section{Eye Movements Results}

First pass fixation duration (summed fixation duration before the eyes left the first word) and total fixation duration (including rereading) were analyzed. The results showed no significant effect of semantic association for first pass fixation duration but a significant difference for total fixation duration; $F(2,38)=12.31, p<.001$. There were shorter fixation $(339 \mathrm{~ms})$ durations on the prime word with nonword targets than with associated $(371 \mathrm{~ms}) ; F(1,19)=9.4, p<.01$, or nonassociated word pairs $(394 \mathrm{~ms}) ; F(1,19)=14.98, p<.001$. More interest- 


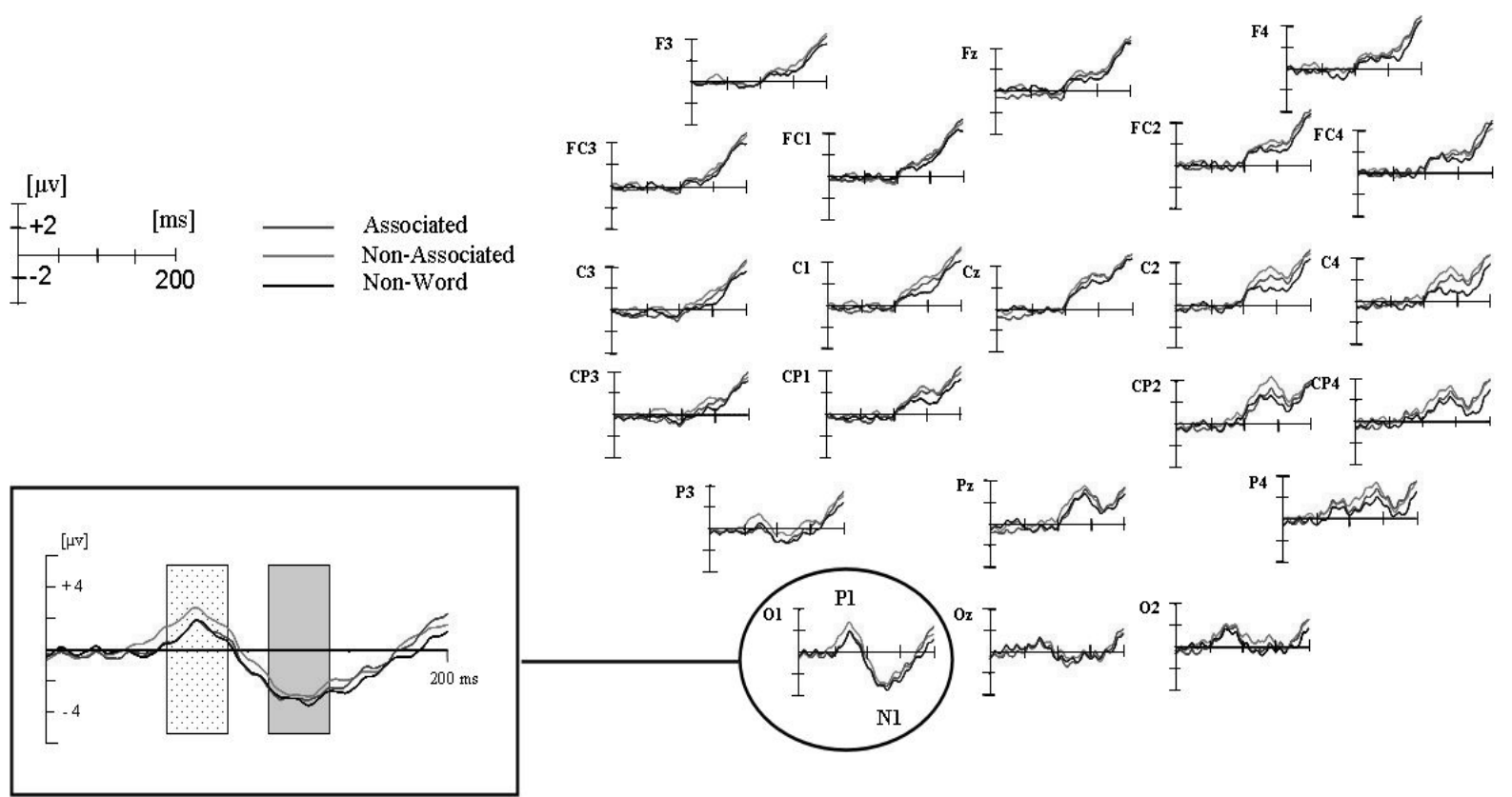

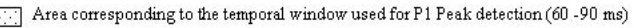

Area corresponding to the temporal window used for N1 Peak detection (110-140 ms)

Figure 3. Grand-averaged ERPs obtained at each electrode in the three experimental conditions (associated, nonassociated, nonword) from 17 subjects. Positive is plotted upward and time zero represents the fixation onset. The temporal window corresponds to the first $200 \mathrm{~ms}$ of the fixation (i.e., time course of the ERPs during $200 \mathrm{~ms}$ following the fixation onset). Grand-averaged ERP waveforms under left occipital electrode $\mathrm{O} 1$ have been plotted in the inserted figure.

Table 1. Mean amplitudes and mean latencies of peak P1/N1 at three sites (frontal, central, posterior) and for each condition (associated, nonassociated, nonword). Values calculated from data obtained on 17 participants.

\begin{tabular}{|c|c|c|c|c|c|c|}
\hline \multirow[b]{2}{*}{ Site Condition } & \multicolumn{3}{|c|}{$\begin{array}{l}\text { Mean Amplitude of Peak P1 }(\mu \mathrm{v} \pm S D) \\
\text { Mean latency of peak P1 }(\mathrm{ms} \pm \pm S D)\end{array}$} & \multicolumn{3}{|c|}{$\begin{array}{l}\text { Mean amplitude of peak } \mathrm{N} 1(\mu \mathrm{v} \pm S D) \\
\text { Mean latency of peak } \mathrm{N} 1(\mathrm{~ms} \pm S D)\end{array}$} \\
\hline & Frontal & Central & Posterior & Frontal & Central & Posterior \\
\hline Associated & $\begin{array}{r}0.5 \pm 1.22 \\
71.1 \pm 10.35\end{array}$ & $\begin{array}{r}0.5 \pm 1.39 \\
67.9 \pm 11.08\end{array}$ & $\begin{array}{r}1.8 \pm 2.48 \\
74.2 \pm 17.10\end{array}$ & $\begin{array}{r}0.0 \pm 2.01 \\
117.0 \pm 12.40\end{array}$ & $\begin{array}{r}0.1 \pm 3.53 \\
118.1 \pm 12.53\end{array}$ & $\begin{array}{r}-2.0 \pm 4.31 \\
120.3 \pm 18.55\end{array}$ \\
\hline Nonassociated & $\begin{array}{r}0.6 \pm 1.21 \\
68.8 \pm 10.46\end{array}$ & $\begin{array}{r}0.7 \pm 1.40 \\
69.8 \pm 10.54\end{array}$ & $\begin{array}{r}2.3 \pm 2.41 \\
74.7 \pm 15.55\end{array}$ & $\begin{array}{l}-0.2 \pm 1.75 \\
113.9 \pm 12.75\end{array}$ & $\begin{array}{r}0.6 \pm 3.02 \\
115.3 \pm 11.59\end{array}$ & $\begin{array}{r}-1.5 \pm 3.64 \\
120.2 \pm 18.63\end{array}$ \\
\hline Nonword & $\begin{array}{r}0.5 \pm 1.88 \\
65.5 \pm 10.78\end{array}$ & $\begin{array}{r}0.5 \pm 2.04 \\
68.0 \pm 11.34\end{array}$ & $\begin{array}{r}1.7 \pm 2.33 \\
73.5 \pm 15.52\end{array}$ & $\begin{array}{l}-0.3 \pm 2.36 \\
116.5 \pm 11.81\end{array}$ & $\begin{array}{r}-0.3 \pm 3.19 \\
117.4 \pm 12.71\end{array}$ & $\begin{array}{r}-2.1 \pm 3.65 \\
120.8 \pm 18.48\end{array}$ \\
\hline
\end{tabular}

Table 2. Mean amplitudes and mean latencies of peak P2/N2 at three sites (frontal, central, posterior) and for each condition (associated, nonassociated, nonword). Values calculated from data obtained on 12 participants.

\begin{tabular}{|c|c|c|c|c|c|c|}
\hline \multirow[b]{2}{*}{ Site Condition } & \multicolumn{3}{|c|}{$\begin{array}{l}\text { Mean amplitude of peak P2 }(\mu \mathrm{v} \pm S D) \\
\text { Mean latency of peak P2 }(\mathrm{ms} \pm S D)\end{array}$} & \multicolumn{3}{|c|}{$\begin{array}{l}\text { Mean amplitude of peak } \mathrm{N} 2(\mu \mathrm{v} \pm S D) \\
\text { Mean latency of peak } \mathrm{N} 2(\mathrm{~ms} \pm S D)\end{array}$} \\
\hline & Frontal & Central & Posterior & Frontal & Central & Posterior \\
\hline Associated & $\begin{array}{r}5.3 \pm 3.05 \\
216.3 \pm 7.62\end{array}$ & $\begin{array}{c}6.0 \pm 3.4 \\
214.0 \pm 9.34\end{array}$ & $\begin{array}{r}5.0 \pm 3.26 \\
214.5 \pm 8.86\end{array}$ & $\begin{aligned} 3.2 & \pm 3.55 \\
262.3 & \pm 9.99\end{aligned}$ & $\begin{aligned} 3.7 & \pm 3.91 \\
262.8 & \pm 9.28\end{aligned}$ & $\begin{array}{r}3.2 \pm 4.02 \\
259.6 \pm 9.99\end{array}$ \\
\hline Nonassociated & $\begin{array}{r}5.2 \pm 2.64 \\
215.6 \pm 7.74\end{array}$ & $\begin{array}{r}4.8 \pm 2.98 \\
217.6 \pm 7.79\end{array}$ & $\begin{array}{r}3.9 \pm 3.17 \\
217.4 \pm 7.66\end{array}$ & $\begin{array}{r}2.18 \pm 2.54 \\
264.1 \pm 8.04\end{array}$ & $\begin{aligned} 1.8 & \pm 3.14 \\
261.48 & \pm 10\end{aligned}$ & $\begin{array}{r}1.9 \pm 3.36 \\
259.6 \pm 9.95\end{array}$ \\
\hline Nonword & $\begin{array}{r}5.1 \pm 3.22 \\
217.0 \pm 7.43\end{array}$ & $\begin{array}{r}5.2 \pm 3.72 \\
215.7 \pm 8.07\end{array}$ & $\begin{array}{r}4.8 \pm 4.17 \\
217.2 \pm 8.41\end{array}$ & $\begin{array}{r}1.81 \pm 3.17 \\
266.5 \pm 7.78\end{array}$ & $\begin{array}{r}2.2 \pm 3.62 \\
263.7 \pm 9.04\end{array}$ & $\begin{array}{r}2.1 \pm 3.88 \\
264.8 \pm 9.19\end{array}$ \\
\hline
\end{tabular}


Left hemisphere

Frontal sites
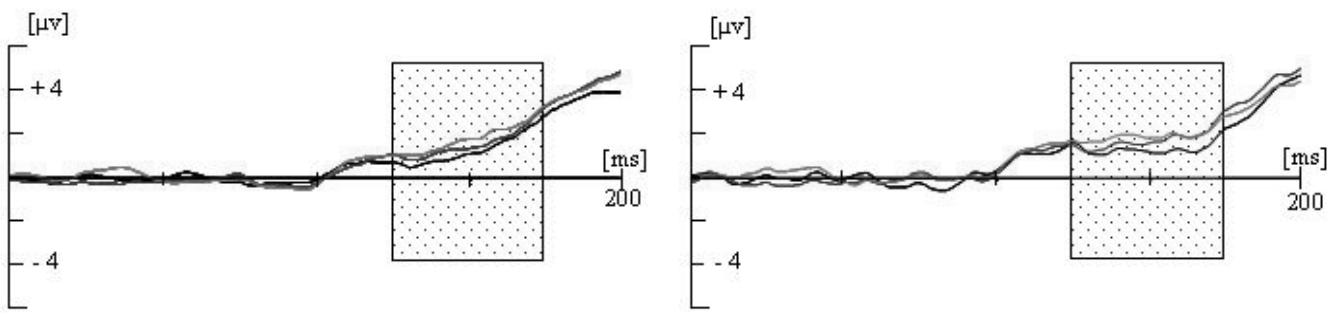

Right hemisphere

Frontal sites
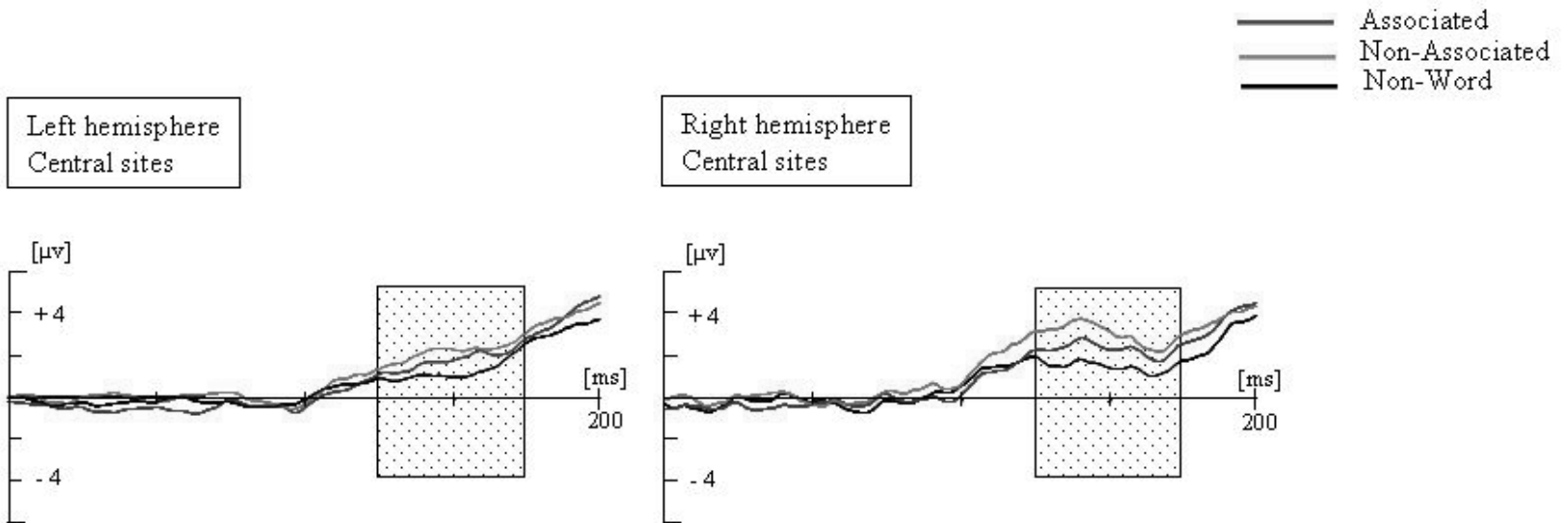

Area corresponding to the temporal window $125-175 \mathrm{~ms}$

Figure 4. Grand-averaged ERP waveforms at frontal and central sites in both hemispheres in the three semantic conditions (associated, nonassociated, nonword). The waveforms were obtained by pooling the ERPs of all electrodes corresponding to a given site during the first $200 \mathrm{~ms}$ following fixation onset. The area represents the temporal window (125-175 ms) used for calculating the mean voltage amplitude.

ingly, total fixation duration was shorter for associated words rather than nonassociated words; $F(1,19)=8.65$, $p<.01$.

\section{Earliest EFRP Components: Temporal Window of 0-200 ms}

The grand averaged ERP waveforms shown in Figure 3 were obtained from the averaged data of 17 subjects. They represent the time course of the ERPs during the $200 \mathrm{~ms}$ following the onset of the fixation. The ERPs revealed that two early components were elicited on posterior sites compared to frontal/central sites. At these posterior sites (mainly on $\mathrm{O} 1 ; \mathrm{P} 3$ shows a similar pattern but with less activation), the graph showed a complex set of positive/negative peaks emerging from the data. Based on the voltage measures taken below electrode $\mathrm{O} 1$, the earliest positive deflection reached its maximum amplitude of $2.6 \mu \mathrm{v}$ with a mean latency of $68 \mathrm{~ms}$, while the negative deflection peaks did so at $119 \mathrm{~ms}$ with a mean amplitude of $-5.07 \mu \mathrm{v}$. Given their latencies and distribution at posterior electrode sites, these peaks were labelled $\mathrm{P} 1$ and $\mathrm{N} 1$, respectively.

In an attempt to reveal a modulation effect of semantic parafoveal processing on these components, omnibus ANOVAs were computed (a) separately for both components (P1/N1) using base-line-to-peak amplitude and (b) using mean amplitude analyses (inside a $125-175 \mathrm{~ms}$ window).

On peak amplitude, comparisons between the left and right hemispheres strongly argued for a left occipital laterality of $\mathrm{P} 1 / \mathrm{N} 1$ components; $F(1,16)=7.12$, $p<0.02$ for $\mathrm{P} 1$, and $F(1,16)=34.45, p<.001$ for $\mathrm{N} 1$. While there was no significant difference between words (associated or nonassociated) and nonwords on P1 amplitude, the difference was nearly significant on N1 amplitude; $F(1,16)=3.52, p=.07$; with a greater negative amplitude for associated words on electrode O1. 


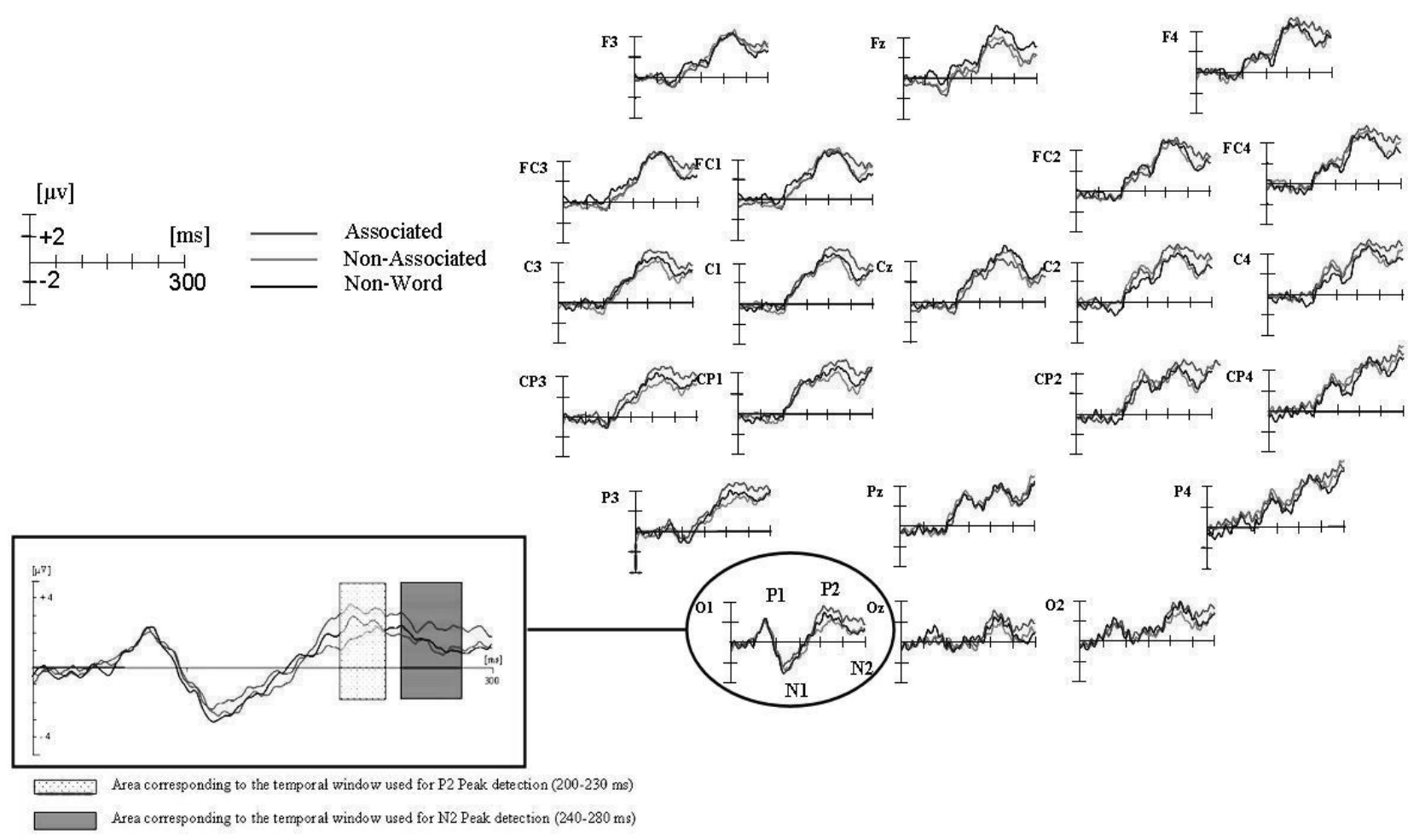

Figure 5. Grand-averaged ERPs obtained at each electrode in the three experimental conditions (associated, nonassociated, nonword) from 12 subjects. Positive is plotted upward and time zero represents the fixation onset. The temporal window corresponds to the first $300 \mathrm{~ms}$ of the fixation (i.e., time course of the ERPs during $300 \mathrm{~ms}$ following the fixation onset). Grand-averaged ERP waveforms under left occipital electrode $\mathrm{O} 1$ has been plotted in the inserted figure.

At central and frontal electrode sites, P1 amplitude was weaker than those observed at posterior electrode sites; $F(1,16)=15.01, p<.001$. As shown in Figure 3 and Figure 4, the main observable component was a positive deflection starting at $100 \mathrm{~ms}$ and reaching its highest amplitude at about $140 \mathrm{~ms}$. ANOVAs were computed using the mean voltage amplitude measured in the 125-175 ms temporal window as the variable (see Figure 4). Contrasting with the P1/N1 components, the analyses showed a highly significant laterality effect with dominance of the right hemisphere; $F(1,16)=$ $7.68, p<0.01$. Interestingly, the semantic association effect was marginally significant; $F(2,32)=3.0, p=$ .063. Planned comparisons indicated stronger activation for nonassociated words compared to nonword conditions; $F(1,16)=5.21, p<.05$, while all the other comparisons failed to reach the significance level $(p>$ $.1)$.

\section{EFRP Components after 200 ms: Temporal Window of 0-300 ms}

The grand average waveforms shown in Figure 5 were obtained from the averaged data of 12 subjects. In fact, five subjects were eliminated from the analyses due to the lack of fixation durations reaching $300 \mathrm{~ms}$. We focused on the last $100 \mathrm{~ms}$ of the fixation duration. Based on the observation of the grand averaged ERP waveforms (see Figures 5 and 6), two major ERP components could be delineated at every electrode site. The first component was labelled P2 and corresponded to a positive deflection starting at about $160 \mathrm{~ms}$ and peaking at $215 \mathrm{~ms}$, with a mean amplitude of $5 \mu \mathrm{v}$. The second component was labelled N2 and corresponded to a negative decline peaking at $260 \mathrm{~ms}$ with a mean amplitude of $2 \mu \mathrm{v}$. No hemisphere dominance or electrode site preference could be detected for either peak. In Table 2, the amplitudes and latencies of each component are given for each electrode site and type of semantic association. If we consider the amplitudes of each peak, we can see that the values were comparatively larger in the associated-word condition. For P2 amplitude, semantically associated words led to greater amplitudes than nonassociated words; $F(1,11)=5.81, p<.05$ (no other pairwise comparisons reached significance, $F_{\mathrm{s}}<1$ ). For N2 amplitude, the same comparison between conditions was not significant, $F(1,11)=2.52$, ns. The analyses comparing the mean amplitudes of these components revealed no significant differences between conditions. 


\section{Left hemisphere \\ Frontal sites}

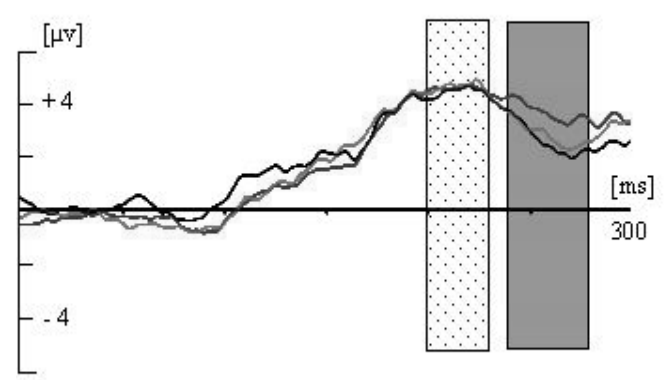

Left hemisphere

Central sites

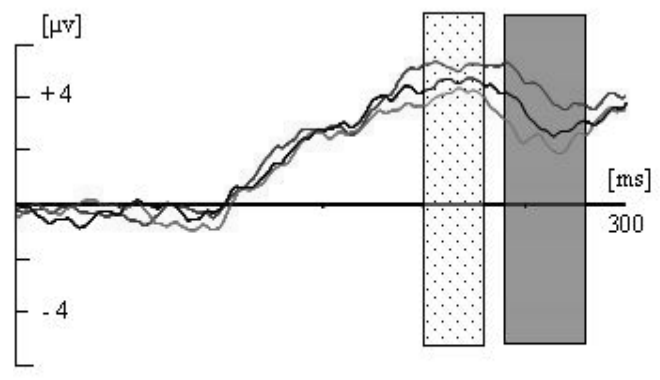

Right hemisphere

Frontal sites

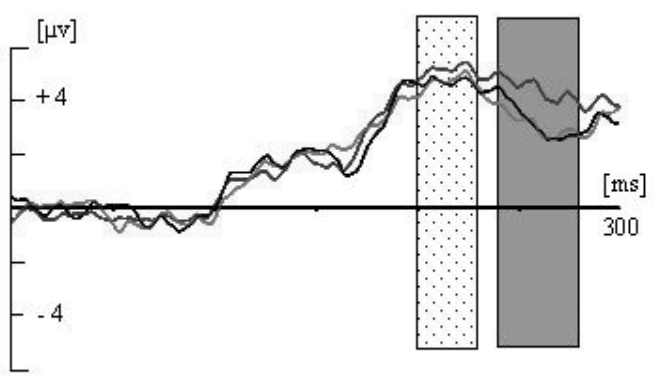

Associated

Right hemisphere

Non-Associated

Central sites

Non-Word

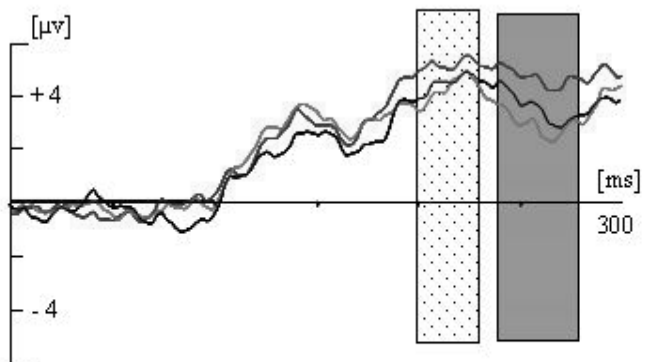

Area corresponding to the temporal window used for P2 Peak detection (200-230 ms)

Area corresponding to the temporal window used for N2 Peak detection (240-280 ms)

Figure 6. Grand-averaged ERP waveforms at frontal and central sites in both hemispheres in the three semantic conditions (associated, nonassociated, nonword). The waveforms were obtained by pooling the ERPs of all electrodes corresponding to a given site during the first $300 \mathrm{~ms}$ following fixation onset. These graphs show the time course of the ERP components during the $300 \mathrm{~ms}$ following the fixation onset. The area represents the temporal windows (200-230 ms and 240-280 ms) used for P2/N2 peak detection.

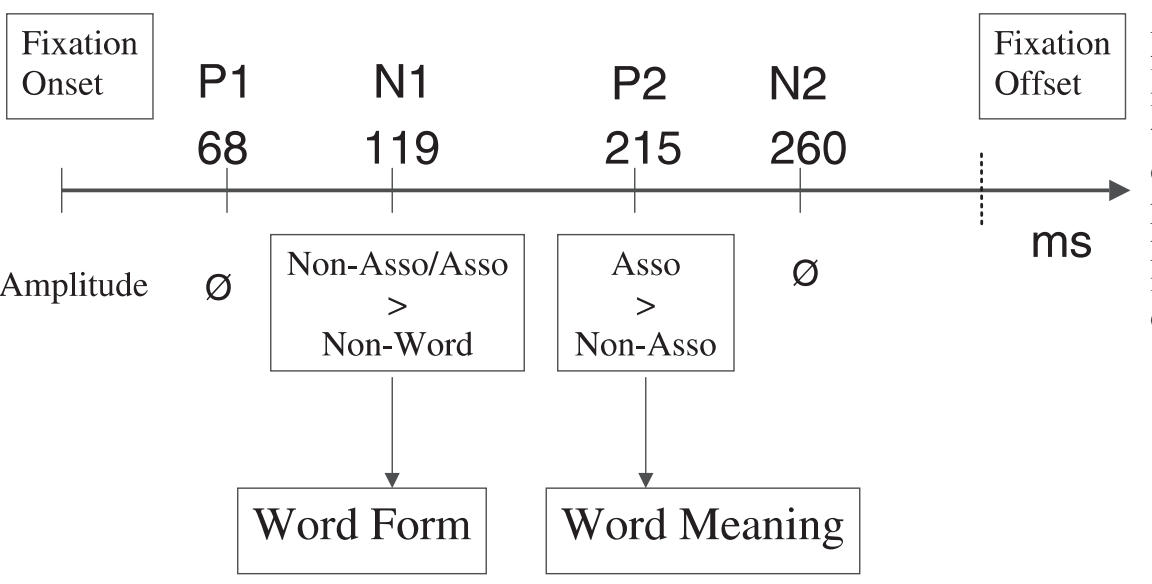

Figure 7. Timeline of the parafoveal-onfoveal effect illustrating the two-step cognitive processes (based on the ERPs obtained under the electrode O1): First, the detection of illegal letter combinations in parafovea took place as soon as $119 \mathrm{~ms}$ poststimulus (N1), and subsequently the meaning of the parafoveal word was accessed around $215 \mathrm{~ms}$ poststimulus (P2). 


\section{Discussion}

The aim of this paper was twofold: (1) to introduce a potential improvement in reading research by coupling an eye-tracking system with an EEG system in order to describe early processing in word identification, and (2) to use this EFRP technique to determine whether words are processed in parallel or sequentially, and to describe the time course of parafoveal-on-foveal effects on attentional/lexical processing.

Most prior ERP studies on language processing have focused on late endogenous components such as the P300 and N400 waveforms (i.e., $400 \mathrm{~ms}$ after stimulus onset). However, the data did not fit well with eye-movement models of reading and the timing of lexical and semantic events, since the fixation duration is shorter and lasts about $250 \mathrm{~ms}$. Thus, it seemed important to examine the early exogenous components to find out about their role in lexical processing. Only a few studies have examined early components (Nobre \& McCarthy, 1994a, b; Sereno \& Rayner, 2000, 2003; Sereno et al., 1998). In particular, Sereno et al. have attempted to establish the time-line of lexical processing during a single fixation and found lexical operations beginning as early as $100 \mathrm{~ms}$. However, their time-line for word recognition seems problematic because they put together eye movements and ERP data from different experiments (although with the same linguistic material) and, thus, from different subjects. In this paper we have tried to bypass this difficulty and get a direct look by coupling an eyetracking system with an EEG system. Moreover, this system bypasses the stimulus presentation constraint of ERP experiments, where stimuli must always be presented in the same location so as to prevent saccade artifacts. With our technique the dynamics of reading can be captured directly by synchronizing ERP data with fixation boundaries (fixation onset and offset detected by the eye-tracking system) and eliminating ERP data acquired during saccades. In sum, our technique zooms into a fixation by describing the activation/inhibition sequence of ERP waveforms underlying lexical processing. To test this possibility, we used our technique to describe a wellknown but controversial effect that takes place during reading, namely the impact of the parafoveal word on the foveal word (parafoveal-on-foveal effects) and to draw the time course of attentional/lexical processing.

Clearly, our results showed that while the analysis of first-pass fixation duration (EM data) was unable to reveal any effects of attention or semantic processing during parafoveal processing, the additional ERP data were sensitive to early lexical processing especially on N1 and P2 components. As early as $119 \mathrm{~ms}$ poststimulus in N1, we found marginal lexical differences on both sites, with stronger activation for associated words than for nonwords under the left occipital electrode O1 (posterior site). Given that the nonwords were made up of strings of illegal letter combinations (such as twsui), this effect might indicate sensitivity to word form in the parafovea. Furthermore, at central and frontal sites, the observed mean amplitudes (P140) confirmed this sensitivity to word form (nonassociated words were more strongly activated than nonwords), which underlines the greater activation in the right hemisphere at these sites. It looks as if these early ERP components were sensitive to any illegal form (nonword) appearing in the parafovea, preventing semantic access and as a consequence inhibiting the activation process.

These data are consistent with previous ERP results showing early lexical processing in components P1 and N1 (Alvarez, Holcomb, \& Grainger, 2003; Neville, Mills, \& Lawson, 1992; Nobre \& McCarthy, 1994a; Rugg, 1983; Sereno, Brewer, \& O’Donnell, 2003; Sereno et al., 1998). For example, the frequency effects reported by Sereno et al. (1998) indicated early sensitivity to word form (P100) when words were compared to nonwords, and a negative brainwave component (N150) sensitive to word frequency when high-frequency words were compared to low-frequency words. More recently, this finding was confirmed by showing word frequency and context effects in the N1 component (Sereno et al., 2003) as early as $132 \mathrm{~ms}$ poststimulus. In the same way, our P140 poststimulus amplitude modulation on the right hemisphere may be very similar to the centroparietal P150 modulation (Proverbio, Vecchi, \& Zani, 2004). At this latency, there were larger responses for words and pseudowords than to letter strings. Proverbio et al. interpreted this component as an index of visual categorization processes being highly sensitive to "ill-formedness" or orthographic regularity of words. Furthermore, a few studies have located this lexical processing on electrodes O1 and O2, especially. Neville et al. (1992) found lexicality differences in the N1, and Nobre et al. (1994), who investigated word type and semantic priming, found differences in the P1. In the ERP literature, components P1 and N1 are usually seen as indexing the visual signal associated with a stimulus, and this visual processing at both foveal and parafoveal stages is thought to be modulated by attention. Studies have shown (Miniussi, Rao, \& Nobre, 2002; Valdes-Sosa, Bobes, Rodriguez, \& Pinilla, 1998) that selective spatial attention has an influence on the visual N1 component. When subjects were asked to focus attention on the center of gaze or toward peripheral locations, the N1 component was strongly affected and modulated foveal stimulus processing. The amount of selective attention may, therefore, change signal-detection parameters (Hawkins, Hillyard, Luck, \& Mouloua, 1990; Miniussi et al., 2002) and may account 
for our parafoveal-on-foveal effects on component N1. Subjects knew they had to trigger a saccade to the target word located on the right before performing a semanticrelatedness task. This task may involve a two-step cognitive procedure: First, detect whether the target word is a legal word using a pattern-matching recognition procedure; then, once the legal form has been recognized (i.e., after N1 activation on left occipital site and P140 modulation on right centrofrontal sites), make the semantic-relatedness judgment between the remaining two legal words (associated words vs. nonassociated words). This second step, which implies higher-level processing, may be reflected by the significant difference between associated words and nonassociated words on the large positive-going wave (P2). This semantic processing would begin as early as $160 \mathrm{~ms}$ poststimulus and would peak at around $215 \mathrm{~ms}$. The time-line sketched by this two-step cognitive processes may be illustrated in Figure 7.

Several studies support this interpretation and have found a large positive component following semantic processing (Alvarez et al., 2003; Rugg, 1987). Alvarez et al. (2003) reported the same P2 component as differentiating three conditions of word repetition (word pairs where the first word belonged to the same language or to another language, or was a different word).

In conclusion, all the effects reported here with this novel technique are compatible with eye-movement models (Morrison, 1984; Reichle et al., 1998) in which visual attention shifts to the next word before reaching it and beginning lexical processing. However, it shows that during this time lapse, semantic preprocessing of the next word is possible and, therefore, suggests parallel processing during reading (Engbert et al., 2002). Because ERPs provide on-line measures of stimulus processing and the corresponding activation/inhibition of cognitive processes, mapping these precise temporal data to eye-movement records enhances the methodology available to cognition studies. Although this technique should be tested further in the future, we believe it will prove valuable for describing the time course of cognitive operations and disentangling the visual, lexical, and attentional factors that have an impact on reading (and perhaps even other activities).

\section{Acknowledgments}

This work was undertaken within the framework of the E-TRACKING project (IST-2001 No. 32323), which is partly funded by the European Commission under the Information Society Technologies 5th Framework Programme and by a Fulbright Scholarship awarded to the first author during his stay at the University of Colorado at Boulder.

\section{References}

Alvarez, R.P., Holcomb, P.J., \& Grainger, J. (2003). Accessing word meaning in two languages: An event-related brain potential study of beginning bilinguals. Brain and Language, 87, 290-304

Cornuejols, M. (1999). La mémoire sémantique et ses modes d'accès (verbal, imagé): approche pluridisciplinaire [Semantic memory and its access modes (verbal, visual): A multidisciplinary approach]. Thèse de Doctorat de Sciences Cognitives [Doctoral dissertation in Cognitive Sciences], Université Paris XI-Orsay.

Engbert, R., \& Kliegl, R. (2001). Mathematical models of eye movements in reading: A possible role for autonomous saccades. Biological Cybernetics, 85, 77-87.

Engbert, R., Longtin, A., \& Kliegl, R. (2002). A dynamical model of saccade generation in reading based on spatially distributed lexical processing. Vision Research, 42, 621-636.

Hawkins, H.L., Hillyard, S.A., Luck, S.J., \& Mouloua, M. (1990). Visual attention modulates signal detectability. Journal of Experimental Psychology: Human Perception \& Performance, 16, 802-811.

Inhoff, A.W., Starr, M., \& Shindler, K.L. (2000). Is the processing of words during eye fixations in reading strictly serial? Perception \& Psychophysics, 62, 1474-1484.

Jasper, H. (1958). The 10-20 electrode system of the international federation. Electroencephalography and Clinical Neurophysiology, 10, 371-375.

Jastrzembski, J.E. (1981). Multiple meanings, number of related meanings, frequency of occurrence, and the lexicon. Cognitive Psychology, 13, 278-305.

Jastrzembski, J.E., \& Stanners, R.F. (1975). Multiple word meanings and lexical search speed. Journal of Verbal learning and Verbal Behavior, 14, 534-537.

Joyce, C., Gorodnitsky, I., King, J., \& Kutas, M. (2002). Tracking eye fixations with electroocular and electroencephalographic recordings. Psychophysiology, 39, 607-618.

Kazai, K., \& Yagi, A. (1999). Integrated effect of stimulation at fixation points on EFRP(Eye-fixation related brain potentials). International Journal of Psychophysiology, 32, 193-203.

Kennedy, A., Pynte, J., \& Ducrot, S. (2002). Parafoveal-on-foveal interactions in word recognition. Quarterly Journal of Experimental Psychology: Human Experimental Psychology, 55A, 1307-1337.

Millis, M.L., \& Button, S.B. (1989). The effect of polysemy on lexical decision time: Now you see it, now you don't. Memory and Cognition, 17, 141-147.

Miniussi, C., Rao, A., \& Nobre, A.C. (2002). Watching where you look: Modulation of visual processing of foveal stimuli by spatial attention. Neuropsychologia, 40, 2448-2460.

Morrison, R.E. (1984). Manipulation of stimulus onset delay in reading: Evidence for parallel programming of saccades. Journal of Experimental psychology: Human Perception and performance, 10, 667-682.

Murray, W.S. (1998). Parafoveal pragmatics. In G. Underwood (Ed.), Eye guidance in reading and scene perception (pp. 181199). Elsevier.

Neville, H., Mills, D., \& Lawson, D. (1992). Fractionating language: Different neural subsystems with different sensitive periods. Cerebral Cortex, 2, 244-258.

Nobre, A.C., \& McCarthy, G. (1994a). Language-related ERPs: 
Scalp distributions and modulation by word-type and semantic priming. Journal of Cognitive Neuroscience, 6, 233.

Nobre, A.C., \& McCarthy, G. (1994b). Word recognition in the human inferior temporal lobe. Nature, 372(6503), 260-263.

Proverbio, A., Vecchi, L., \& Zani, A. (2004). From orthography to Phonetics: ERP measures of grapheme-to-phoneme conversion mechanisms in reading. Journal of Cognitive Neuroscience, 16, 301-317.

Rayner, K. (1998). Eye movements in reading and information processing: 20 years of research. Psychological Bulletin, 124, 372-422.

Reichle, E.D., Pollatsek, A., Fisher, D.L., \& Rayner, K. (1998). Toward a model of eye movement control in reading. Psychological Review, 105, 125-137.

Reichle, E.D., Rayner, K., \& Pollatsek, A. (2002). The E-Z reader model of eye movement control in reading: Comparisons to other models. Behavioral and Brain Sciences.

Rugg, M.D. (1983). Further study of the electrophysiological correlates of lexical decision. Brain \& Language, 19, 142-152.

Rugg, M.D. (1987). Dissociation of semantic priming, word and nonword repetition effects by event-related potentials. Quarterly Journal of Experimental Psychology: Human Experimental Psychology, 39, 123-148.

Sereno, S., Brewer, C., \& O'Donnell, P. (2003). Context effects in word recognition: Evidence for early interactive processing. Psychological Science, 14, 328-333.

Sereno, S., \& Rayner, K. (2000). The when and where of reading in the brain. Brain and Cognition, 42, 78-81.

Sereno, S., \& Rayner, K. (2003). Measuring word recognition in reading: Eye movements and event-related potentials. Trends in Cognitive Sciences, 7, 489-493.
Sereno, S., Rayner, K., \& Posner, M.I. (1998). Establishing a timeline of word recognition: Evidence from eye movements and event-related potentials. Neuroreport, 9, 2195-2200.

Valdes-Sosa, M., Bobes, M.A., Rodriguez, V., \& Pinilla, T. (1998). Switching attention without shifting the spotlight: Objectbased attentional modulation of brain potentials. Journal of Cognitive Neuroscience, 10, 137-151.

Yagi, A., Imanishi, S., Konishi, H., Akashi, Y., \& Kanaya, S. (1998). Brain potentials associated with eye fixations during visual tasks under different lighting systems. Ergonomics, 41, 670-677.

Yagi, A., \& Ogata, M. (1995). Measurement of work load using brain potentials during VDT tasks. In Y. Anzai, K. Ogawa, \& H. Mori (Eds.), Symbiosis of human and artifact. Hyogo: Elsevier.

Accepted for publication: February 22, 2005

Address for correspondence

Thierry Baccino and Yves Manunta

University of Nice Sophia-Antipolis

LPEQ (EA 1189)

24, Av des Diables Bleus

F-06327 Nice

France

Tel. +33 4 9200-1204

Fax +33 4 9200-1297

E-mail baccino@unice.fr 